\title{
Dynamic Energy Management in Cloud Data CENTERS: A SURVEY
}

\author{
T.Veni ${ }^{1}$ and S. Mary Saira Bhanu ${ }^{2}$ \\ Department of Computer Science and Engineering \\ National Institute of Technology Tiruchirappalli \\ Tiruchirappalli-620015, India \\ $\{406111001$, msb\}@nitt.edu
}

\begin{abstract}
Cloud data centers have become indispensable infrastructure for computing and data storage that facilitate the development of diversified services offered by the cloud. These data centers consume enormous amounts of electrical energy to process the cloud services resulting in large amount of $\mathrm{CO}_{2}$ emissions, high operational cost, and affecting the lifetime of hardware equipments. This necessitates the development of efficient energy management techniques in cloud data centers for both economic and environmental standpoints. Energy management at data centers can be static or dynamic. Energy consumption can be reduced by employing dynamic energy management techniques both in hardware and software levels at cloud data centers. This paper surveys various issues related to dynamic energy management in cloud data centers.
\end{abstract}

\section{KEYWORDS}

Cloud Data Center, Virtualization, Dynamic Energy Management, \& Server Consolidation

\section{INTRODUCTION}

Data Centers have emerged as a back-bone infrastructure, housing large number of IT equipments such as servers, data storage, network devices, power and cooling devices etc. that facilitate the development of wide variety of services offered by the cloud [1] Currently, several service providers such as Amazon, Google, Yahoo, Microsoft, IBM and Sun, have their own data centers to provide the scalable services to a large customer base [2-3]. With the rapid development of IT industry and increasing demand for cloud services, the number of data centers have increased. These data centers consume enormous amount of energy to process its services resulting in increased energy consumption. The surging energy consumption of these data centers has become a serious concern from both economic and environmental standpoints.

According to McKinsey report [4], the energy consumption of data centers is $\$ 11.5$ billion in 2010 and it doubles every five years. Gartner [5] also estimated that world wide IT infrastructures are responsible for $2 \%$ of global $\mathrm{CO}_{2}$ emissions and energy related costs account for the $12 \%$ of the total economical expenditures. The excessive energy consumption at data centers leads to high operational cost, large amount of $\mathrm{CO}_{2}$ emission and falling lifetime of hardware equipments. 
International Journal on Cloud Computing: Services and Architecture (IJCCSA), Vol.3, No.4, August 2013

Hence, it is necessary to design energy-efficient data centers not only for ensuring system reliability but also reducing environmental impact and operational cost.

Energy management techniques at the data centers can be static or dynamic. The static energy management techniques fail to address the run time adaptation of data centers in response to workload changes. The dynamic energy management techniques configure the data center at both hardware and software levels dynamically based on workload variability.

Further, the energy conservation can be achieved by efficient utilization of data center resources. Virtualization technology is one such powerful technology to address this energy inefficiency by increasing resource utilization [6].This technology allows multiple virtual machines (VMs) to share the resources on a single physical machine (PM). The features such as VM isolation and VM migration along with dynamic resource provisioning can be used either to consolidate virtual machines on fewer physical servers or to balance the load across physical servers in data centers, thereby ensuring applications' performance. This paper surveys the various techniques and issues related to dynamic energy management in cloud data centers.

The rest of this paper is organized as follows. Section 2 explains taxonomy of energy management mechanisms in virtualized data centers; section 3 presents an overview of dynamic energy management techniques in cloud data centers and finally, section 4 presents the conclusion.

\section{TAXonomy of Energy Management TechniQues in Cloud Data CENTERS}

It is necessary to understand the background terminologies involved in the context of energy management techniques. The energy consumption (E) at cloud data center is defined as a total amount of power $(\mathrm{P})$ consumed over a period of time $(\mathrm{T})$ while performing the work [7], i.e.,

$$
\mathrm{E}=\mathrm{P} * \mathrm{~T}
$$

Thus, the energy conservation at the cloud data centers can be achieved by controlling average power consumption (P) over the period of time. As per taxonomy [7], the energy management approaches in cloud data center can be classified into static and dynamic energy management techniques as shown in Fig.1. 
International Journal on Cloud Computing: Services and Architecture (IJCCSA), Vol.3, No.4, August 2013

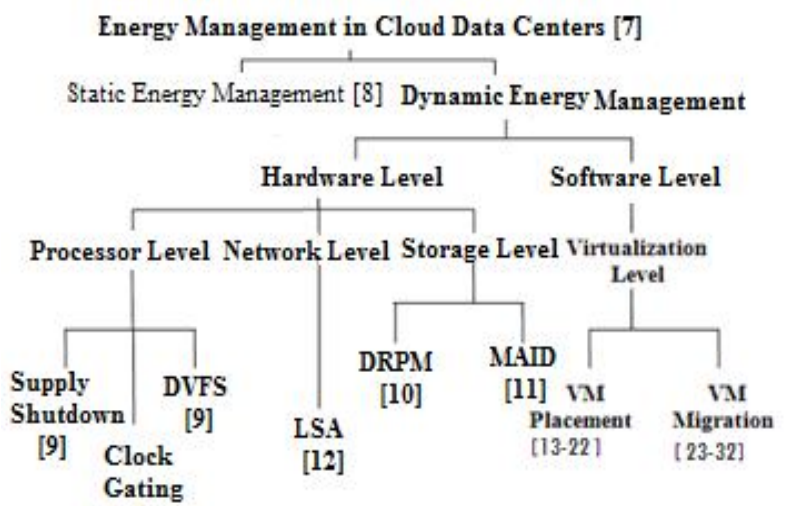

[9]

Fig .1. Taxonomy of Energy Management Techniques in Cloud Data Centers

Static Energy Management (SEM) technique [8] uses low-power hardware components at the data centers for energy savings. The request for the cloud services running in the data center is volatile in nature. This technique fails to address the runtime adaptation of data centers in response to the service demand to avoid resource wastage and it is also a very expensive technique for energy conservation.

\section{OVERVIEW OF DYNAMIC ENERgy MANAGEMENT TECHNIQUES}

Dynamic energy management (DEM) techniques dynamically reconfigure the system based on current resource requirements of the requested services. It utilizes the power scalable hardware components and software approaches to optimize the energy consumption at data centers.DEM techniques are classified into hardware and virtualization assisted techniques based on the level of their applicability.

\subsection{Hardware Level Energy Management Techniques}

The energy management techniques need to be applied on each hardware components such as the processors, network equipments, and storage devices to reduce overall hardware level energy consumption at cloud data centers.

\subsubsection{Processor Level}

Energy consumption of a processor consists of two components such as static power and dynamic power depends on the usage of various resources at server [7]. The dynamic power consumption of a CMOS-based processor is given by

$$
\text { Dynamic Power }=\mathrm{A} * \mathrm{~F} * \mathrm{C} * \mathrm{~V}^{2}
$$

Where $\mathrm{A}$ is the percentage of active gates, $\mathrm{F}$ is clock frequency of the processor, $\mathrm{C}$ is capacitance load of the processor, and V is the voltage supplied. The techniques such as Dynamic Voltage and Frequency Scaling (DVFS), Network Level Clock Gating and Supply Shutdown are used for power management in processor level. 


\subsubsection{Network Level}

As the size of the data center and network infrastructure is exploding, it is necessary to address the energy consumed by the network devices such as routers, switches, NIC, etc. Switches form the basis of interconnection fabric that delivers job requests to the computing servers for execution. The energy consumption of a switch depends on the type of switch, number of ports, port transmission rates and employed caching solutions. The energy consumed by a switch can be generated by the following equation;-

$$
\mathrm{P}_{\text {Switch }}=\mathrm{P}_{\text {Chassis }}+\mathrm{N}_{\text {Line cards }} * \mathrm{P}_{\text {Line card }}+\sum_{\mathrm{i}=0}^{\mathrm{R}} \mathrm{N}_{\text {Ports }} * \mathrm{P}_{\mathrm{r}}
$$

Where $\mathrm{P}_{\text {Chassis }}$ is the power consumed by the switch base hardware, $\mathrm{P}$ Line card is the power consumed by the active line card and $\mathrm{P}_{\mathrm{r}}$ is the power consumed by the active ports. The techniques such as Link State Adaptation (LSA), Idle Elements Shutdown are used for power savings in network level.

\subsubsection{Storage Level}

The storage devices constitute a significant fraction of the overall energy budget. The storage level energy management techniques [38] can be divided as follows:-

- Hardware based techniques increase the disk power conservation by maintaining storage hierarchy to strike the right balance between performance and power consumed by storage resources

- Disk management techniques introduce the new disk management layer on top of the file system, which controls disk configuration and data layout to achieve power optimal disk access patterns

- Caching techniques reduce the power consumption at storage level by allowing large fractions of the storage system to remain idle for longer periods of time and switch to lower power modes 


\subsubsection{Summary of Hardware Level Energy Management Techniques}

\begin{tabular}{|c|c|c|c|}
\hline $\begin{array}{l}\text { System } \\
\text { Resources } \\
\text { Considered }\end{array}$ & References & Techniques used & Description \\
\hline \multirow[t]{3}{*}{$\begin{array}{l}\text { Processor } \\
\text { Level }\end{array}$} & $\begin{array}{l}\text { Benini et al } \\
{[9]} \\
\text { Beloglazov } \\
\text { et al[7] }\end{array}$ & $\begin{array}{l}\text { Dynamic Voltage } \\
\text { and Frequency } \\
\text { Scaling (DVFS) }\end{array}$ & $\begin{array}{l}\text { In DVFS, the voltage and frequency of } \\
\text { the processor can be scaled } \\
\text { dynamically depending on the request } \\
\text { that is being processed. }\end{array}$ \\
\hline & $\begin{array}{l}\text { Benini et al } \\
{[9]}\end{array}$ & $\begin{array}{l}\text { Network Clock } \\
\text { Level Gating }\end{array}$ & $\begin{array}{l}\text { In Network Level Clock Gating, the } \\
\text { supplied voltage or the clock frequency } \\
\text { is reduced for idle components. }\end{array}$ \\
\hline & $\begin{array}{l}\text { Benini et al } \\
{[9]}\end{array}$ & Supply Shutdown & $\begin{array}{l}\text { In Supply Shutdown, the idle } \\
\text { components are powered off to } \\
\text { decrease power dissipation as there is a } \\
\text { leakage of current even if all the clocks } \\
\text { are halted. }\end{array}$ \\
\hline \multirow[t]{3}{*}{$\begin{array}{l}\text { Network } \\
\text { Level }\end{array}$} & $\begin{array}{l}\text { Nordmen et } \\
\text { al[12], }\end{array}$ & $\begin{array}{l}\text { Link } \text { State } \\
\text { Adaptation } \\
\text { (LSA) }\end{array}$ & $\begin{array}{l}\text { In LSA, the link speed of network can } \\
\text { be changed dynamically to reduce } \\
\text { energy consumption in networks. }\end{array}$ \\
\hline & $\begin{array}{l}\text { M. Gupta et } \\
\text { al [35] }\end{array}$ & $\begin{array}{l}\text { Switch } \\
\text { Shutdown }\end{array}$ & $\begin{array}{l}\text { In Switch Shutdown, the Ethernet } \\
\text { switches are shutdown dynamically } \\
\text { based on the traffic arrivals, buffer } \\
\text { capacity and bounded maximum } \\
\text { packet delay for energy conservation. }\end{array}$ \\
\hline & $\begin{array}{l}\text { Heller et al } \\
{[36]}\end{array}$ & $\begin{array}{l}\text { LSA }+ \text { Idle } \\
\text { elements } \\
\text { shutdown }\end{array}$ & $\begin{array}{l}\text { This hybrid approach uses both LSA } \\
\text { and Switch shutdown methods to } \\
\text { conserve energy on network level. }\end{array}$ \\
\hline \multirow[t]{3}{*}{$\begin{array}{l}\text { Storage } \\
\text { Level }\end{array}$} & $\begin{array}{l}\text { Gurumathi et } \\
\text { al [10] }\end{array}$ & $\begin{array}{l}\text { Dynamic } \\
\text { Rotations Per- } \\
\text { Minute(DRPM) }\end{array}$ & $\begin{array}{l}\text { In DRPM, the speed of disk rotation } \\
\text { can be changed dynamically per } \\
\text { minute (RPM) for controlling the } \\
\text { power explored in the spindle motor } \\
\text { driving the platters. }\end{array}$ \\
\hline & $\begin{array}{l}\text { Colarelli et al } \\
\text { [11] }\end{array}$ & $\begin{array}{l}\text { Massive } \\
\text { Idle }\end{array}$ & $\begin{array}{l}\text { In MAID, only those disk drives in } \\
\text { active use are spinning at any given } \\
\text { time. MAID reduces power } \\
\text { consumption and prolongs the lives } \\
\text { of the drives. }\end{array}$ \\
\hline & $\begin{array}{l}\text { Bianchini et } \\
\text { al[37] }\end{array}$ & $\begin{array}{l}\text { Popular Data } \\
\text { Concentration } \\
\text { (PDC) }\end{array}$ & $\begin{array}{l}\text { This method selects the most popular } \\
\text { files based on frequency of disk } \\
\text { access and least popular disks are } \\
\text { shutdown for energy conservation. }\end{array}$ \\
\hline
\end{tabular}

Table.1. Summary of Hardware Level Energy Management Techniques 
International Journal on Cloud Computing: Services and Architecture (IJCCSA), Vol.3, No.4, August 2013

For efficient energy conservation, the hardware energy management techniques should consider all resources such as Processor, Network and Storage etc. The above mentioned hardware techniques are applicable at individual server level for energy conservation. Hence, these hardware level energy management techniques do not contribute much in total energy conservation at cloud data centers. The energy consumption can be further reduced by applying energy management techniques at software (virtualization level) at cloud data centers.

\subsection{Virtualization Level Energy Management Techniques}

The energy consumption problem has been addressed partially by making improvements in the physical infrastructure of modern data centers. According to Open Compute project report [33], 93\% of the data center's energy consumption depends upon efficient utilization of computing resources at data centers. Virtualization is a key technology that facilitates the better use of available data center resources using the technique called server consolidation [13]. This technique involves consolidating multiple physical server workloads into single physical server to increase the resource utilization. Thus, it allows for reduction in the total number of physical server used, minimizes the server sprawl as well as total data center space requirements. The server consolidation can be performed either statistically or dynamically.

- In static consolidation, VMS are placed on physical servers for a long time period and not migrated even if workload changes.

- In dynamic consolidation, VMs are placed on physical servers at runtime and migrations of VMs performed automatically in response to the current workload demands. This helps in utilizing the data centers resources efficiently.

The steps for server consolidation (Fig.2.) are as follows:

- Determining the capacities of VM (VM sizing) for running applications and placing of VMs on PM based on their requirements

- Monitoring and profiling the resource utilization for hotspot detection (overloaded and under loaded PMs)

- Resize and remap the VM to another PM.

The VM placement and VM migration act as backbone to VM consolidation process. The challenges for efficient VM consolidation are:-

- Finding the proper VM- to-PM mappings to minimize the acceptable cost function

- Dynamic hotspot detection

- Performing VM migration process with minimal service downtime and resource consumption during migration process 
International Journal on Cloud Computing: Services and Architecture (IJCCSA), Vol.3, No.4, August 2013

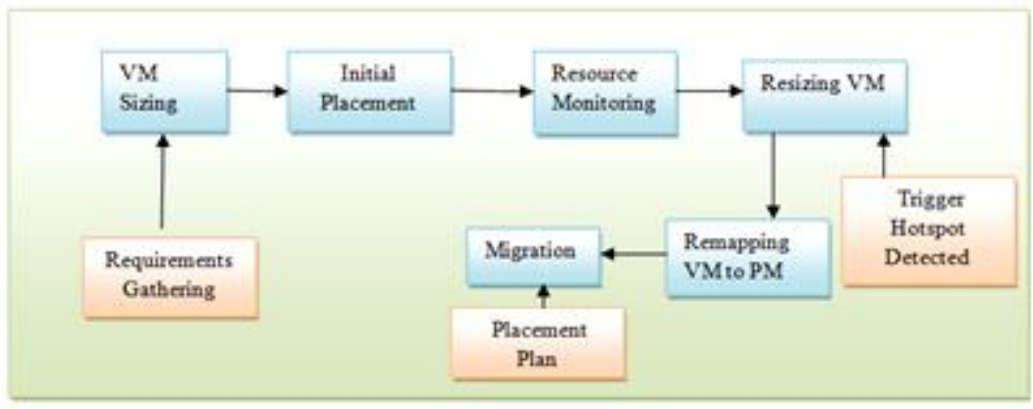

Fig.2. Server Consolidation Steps

\subsubsection{Virtual Machine Placement}

VM placement [14] is the process of mapping VMs to PMs. The placement approach should consider multiple resources such as CPU, memory, disk storages and network bandwidth to reduce the energy consumption at data centers and also needs to maintain the energy performance tradeoff.

The VM placement involves two main steps:

- Provisioning of resources for the virtual machines according to the capacity requirements of corresponding applications (VM sizing)

- Actual placement of VMs onto PMs.

VM placement problem is a NP -Hard problem [34] and no optimal solution exists for it. A set of heuristics is used to solve VM placement problem.

\subsubsection{State- of-the Art in VM Placement}

The energy conservation at data centers increases by maintaining optimal placement of the VMs on the PM. The existing VM placement heuristics are classified into the following:-

- Availability aware VM placement - The main challenge of the VM placement algorithms is to identify suitable VM-PM mapping so as to satisfy workload demands of various applications. Once the hotspot is detected in source PM, the VM placement algorithm finds the workload demands of each VM and identifies the target PM based on the resources availability such as CPU, memory, network and disk [13-17].

- Affinity aware VM placement can be achieved by considering both availability of VM's resources and relationship among VMs. This approach improves the response time of the applications and optimizes the usage of resources. If a hotspot has occurred because of network resource crunch among PMs, then placing two communicating VMs on the same PM will reduce the network overload. In [15] [20], the intra and inter-PM network traffic and also network topology has been considered for VM placement. In [17] [19], the inter 
International Journal on Cloud Computing: Services and Architecture (IJCCSA), Vol.3, No.4, August 2013

memory sharing VMs are identified and placed on a single PM. This reduces the number of servers and memory resource used.

- Workload aware VM placement- The efficient VM consolidation can be accomplished by considering workload interference between co-located VMs to avoid performance degradation. In workload aware VM placement mechanism, the different combination of workload mix such as CPU, I/O intensive, etc., are investigated in order to find optimal VM placement. The benefits of workload mixing can be proactively predicted by using machine learning algorithms which can be used for VM placement decisions [21] [22].

\subsubsection{Analysis}

The VM placement algorithms are analyzed based on the following parameters:-

- Resources availability: the availability of resources (CPU, memory, network and disk of PM determines the number of VMs on it.

- Heterogeneity of PMs

- Workload type of VMs

An efficient VM placement algorithm should consider all the above mentioned parameters during VM placement, but most of the existing VM placement algorithms have not considered the all parameters.

\subsubsection{Virtual Machine Migration}

VM migration [23] has become an indispensable tool that facilitates resource management at cloud data centers for a wide variety of key scenarios such as load balancing, fault- tolerance, hot spot mitigation and server consolidation. The VM migration can be either offline or live. The offline VM migration follows traditional suspend and resume mechanism which increases service down time, causes performance degradation of applications running in VM. Live migration relocates the VM from source to target PM without disturbing the applications running in the VM resulting in minimal downtime. In live migration process, the virtual disks are stored on some shared storage such as Network File Systems, which is accessible from entire network. Hence, virtual disks are not transferred. The steps of Live migration are as follows (Fig. 3):-

1. Once migration process is triggered, source PM transfers the VM's memory pages to target PM without suspending the VM (and hence it is called live migration). The dirtied memory pages during the migration process are transferred to target PM which leads to multiple iterations. This is known as iterative precopy-phase.

2. This iterative process ends and enters into suspend -and- copy phase when either one of the following conditions occurs:

a. The number of pre-copy iterations are greater than the fixed threshold value (n)

b. The network traffic generated is greater than the multiples of VM size

c. The memory page dirty rate is greater than a memory transmission rate

d. The number of memory pages dirtied during current iteration becomes smaller than a predefined threshold 
International Journal on Cloud Computing: Services and Architecture (IJCCSA), Vol.3, No.4, August 2013

3. In suspend-and-copy phase, the VM being migrated is suspended in the source PM and the remaining dirty memory pages as well as the state of the CPU register are transferred to the target PM. Once the migration process is completed, the target PM resumes the VM.

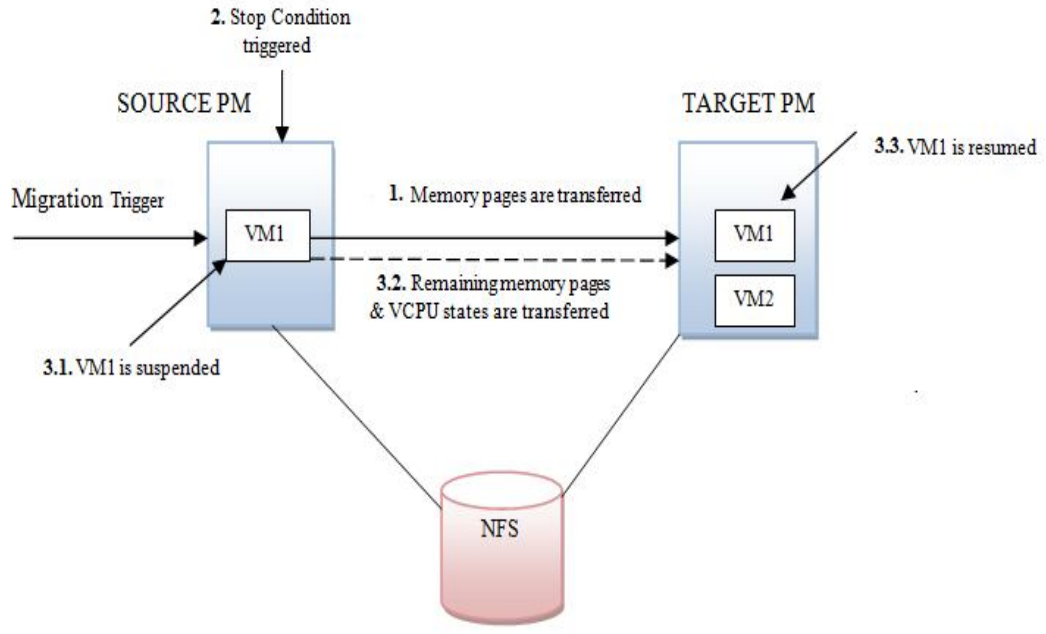

Fig. 3. Live Virtual Machine Migration Mechanism

\subsubsection{State-of- the Art in Live Migration Research}

It is hard to provide a quick live VM migration with less resource overhead because large amount of data transfer during migration results in performance degradation of VM applications. The response time and throughput of the data center applications heavily depends on the VM migration process. Hence, it is essential to improve the performance of migration process to facilitate efficient resource management at data centers.

\subsection{Optimizations of Live Migration}

Many methods have been proposed to improve live migration and optimize its performance metrics such as total migration time and downtime to provide uninterruptible services to applications running in VMs.

- Memory compression: Live migration performance is improved by minimizing the amount of data transfer to the destination using the technique called memory page compression [24]. This technique compresses the source PM memory pages to minimize the amount of data during live migration process and decompresses the memory pages in target PM. However, the performance of application running in VM depends on selection of suitable compression and decompression algorithms, resources availability and workload characteristics. The changes in workload characteristics introduce significant resource overhead during compression and decompression process leads to performance degradation of applications running in VM. Therefore, it is necessary to ensure trade-off between resource overhead and compression effects to achieve efficient migration. 
International Journal on Cloud Computing: Services and Architecture (IJCCSA), Vol.3, No.4, August 2013

- Delta page transfer: This technique reduces the network bandwidth consumption by maintaining a cache of previously transferred memory pages. This optimizes the transmission of dirtied pages by sending the difference between cached page content and page content that is going to be transferred. This improves the live migration process with reduced risk of service interruption [25][32].

- Data deduplication: This technique finds identical data inside the memory and disk of a single VM and removes that duplicates during the live migration process. The performance of this technique depends on selection of suitable techniques for finding identical data on memory and disk contents [31-32].

- Post-Copy Approach: This approach postpones the memory page transfer phase until after the VM's CPU state has been transferred to the target PM and resumed there. The performance of post-copy approach depends on the way and which the memory pages are fetched from source PM during live migration process. There are three main ways the memory pages are fetched from source PM [26].

- Post-copy via demand paging- The page faults are serviced by requesting the referenced page over the network from the source node

- Post-copy via active pushing- This technique, proactively pushes the memory pages from source to the target, while VM continues executing at the target PM

- Post-copy via prepaging- This approach extends the active pushing technique by estimating the spatial locality of the VM's memory access pattern in order to anticipate the occurrence of major page faults

The post-copy approach ensures that each memory page is transferred at most once, hence avoiding the duplicate transmission overhead of pre-copy approach. However, this approach does not have the reliability as Pre-Copy approach because VM cannot restart in the source $\mathrm{PM}$, if the destination PM crashes.

- Hybrid pre and post copy: This hybrid approach performs single round of pre-copying which precedes the virtual CPU state transfer. This is followed by post-copying of the remaining dirty pages from the source PM. Therefore, it gets the benefits of both approaches and improves live migration process [27].

\subsection{Multiple VM Migrations}

Whenever there is a need to shift entire virtual clusters to different locations, it requires large amount of data to be transferred over the network which results in network and CPU overhead. This leads to performance degradation of applications running in the PM. Hence, the identical contents of co-located VMs in the physical machine can be pro-actively tracked and transferred only once to the target PM. This improves the performance of multiple VM migration. This is known as "Gang Scheduling" of virtual machines [27-32]. It optimizes both memory and network overhead of migration.

\subsection{Migration in Network}

Several enterprises have data centers that are spread across the world to offer efficient services to worldwide users. The network can be LAN or WAN. Live migration of VMs across worldwide data centers entails transferring virtual CPU, memory state and disk state to target PM and also it 
International Journal on Cloud Computing: Services and Architecture (IJCCSA), Vol.3, No.4, August 2013 necessitates network re-configuration as the VM shifts into a new subnet where a new IP address is assigned to the VM [29-30] [32].

\subsubsection{Analysis}

The live migration process consumes resources such as CPU and network which can seriously impact the performance of both the VM being migrated as well as other VMs in the PM. The performance of the migration approach depends on the parameters such as

- VM size consumes significant amount of CPU and network resources during live migration process. Thus, an optimal VM size needs to be selected to reduce resource overhead during migration process.

- Page dirty rate indicates the rate at which memory pages are dirtied in source PM during migration process. If page dirty rate increases, it results in more data being sent per iteration over the network, results in increasing of total migration time

- Available network capacity between source and target PM

- Available CPU resource at both source and target PM

The following performance metrics should be considered to evaluate performance of live migration process;-

- Migration time- the time between initiation of migration and successful completion

- Service downtime - the time for which service is unavailable during migration

- CPU and network resource consumption during migration process

\begin{tabular}{|c|c|c|c|c|c|c|c|c|c|c|c|c|}
\hline \multirow[t]{2}{*}{ Reference } & \multirow[t]{2}{*}{ Techniques used } & \multicolumn{4}{|c|}{ Parameters considered } & \multicolumn{3}{|c|}{$\begin{array}{l}\text { Performance metrics } \\
\text { accounted }\end{array}$} & \multirow{2}{*}{$\begin{array}{c}\text { Single } \\
\text { vyly } \\
\text { Multiple } \\
\text { val }\end{array}$} & \multicolumn{3}{|c|}{ WAX } \\
\hline & & $\begin{array}{l}\text { VMI } \\
\text { size }\end{array}$ & $\begin{array}{l}\text { Page } \\
\text { dirty } \\
\text { rate }\end{array}$ & $\begin{array}{l}\mathrm{X} / \mathrm{W} \\
\text { traffic }\end{array}$ & $\begin{array}{l}\text { CPC } \\
\text { egeles }\end{array}$ & 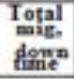 & $\begin{array}{l}\text { N/W } \\
\text { BW }\end{array}$ & $\begin{array}{l}\text { CPU } \\
\text { utal }\end{array}$ & & YN & $\frac{\pi}{1}$ & $\begin{array}{l}\text { stor } \\
\text { age }\end{array}$ \\
\hline $\begin{array}{l}\text { clark et al } \\
\text { (23) }\end{array}$ & Pre copy & & $\checkmark$ & $\checkmark$ & & $\checkmark$ & & & $\begin{array}{l}\text { Single } \\
\mathrm{VM}\end{array}$ & No & & \\
\hline $\begin{array}{l}\text { Jin et al } \\
\text { [24] }\end{array}$ & $\begin{array}{l}\text { Precopy } \\
\text {-memory } \\
\text { compression }\end{array}$ & & $\checkmark$ & & & $\checkmark$ & & & $\begin{array}{l}\text { Single } \\
\mathrm{VM}\end{array}$ & No & & \\
\hline $\begin{array}{l}\text { Hackinget } \\
\text { al [25] }\end{array}$ & $\begin{array}{l}\text { Pre copy-delta } \\
\text { pagetransfer }\end{array}$ & & $\checkmark$ & $\checkmark$ & & $\checkmark$ & $\checkmark$ & & $\begin{array}{l}\text { Multipl } \\
\text { e VM }\end{array}$ & Yes & & $\checkmark$ \\
\hline $\begin{array}{l}\text { Himes et al } \\
\text { [26] }\end{array}$ & $\begin{array}{l}\text { Post copy } \\
\text { adaptive } \\
\text { prepaging } \\
\text {-dynamic self } \\
\text { ballooning }\end{array}$ & & 2 & & & 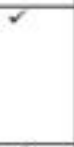 & & & $\begin{array}{l}\text { Single } \\
\mathrm{VM}\end{array}$ & No & & \\
\hline $\begin{array}{l}\text { Sahni et al } \\
{[27]}\end{array}$ & $\begin{array}{l}\text { Precopy+post } \\
\text { copy }\end{array}$ & & 7 & & & 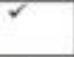 & & & $\begin{array}{l}\text { Single } \\
\text { VM }\end{array}$ & No & & \\
\hline $\begin{array}{l}\text { Deshpande } \\
\text { et al [28] }\end{array}$ & $\begin{array}{l}\text { Precopy+mulrip } \\
\text { le migrations }\end{array}$ & & $\checkmark$ & $\checkmark$ & & $\checkmark$ & $\checkmark$ & & $\begin{array}{l}\text { Multipl } \\
\text { e VM }\end{array}$ & No & & \\
\hline $\begin{array}{l}\text { Riteau et al } \\
\text { [29] }\end{array}$ & $\begin{array}{l}\text { Precopy+conten } \\
\text { tbashed } \\
\text { hashing }\end{array}$ & & 2 & & & r & & & $\begin{array}{l}\text { Multipl } \\
\text { e VM }\end{array}$ & yes & & 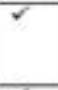 \\
\hline $\begin{array}{l}\text { Bradford et } \\
\text { al }[30]\end{array}$ & $\begin{array}{l}\text { Write throttling } \\
\text { - DNS and IP } \\
\text { tumneling }\end{array}$ & & 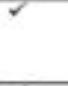 & 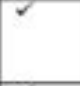 & & 8 & 5 & & $\begin{array}{l}\text { Multipl } \\
\text { e VM }\end{array}$ & yes & 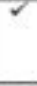 & $\gamma$ \\
\hline $\begin{array}{l}\text { Woodet al } \\
\text { [32] }\end{array}$ & $\begin{array}{l}\text { Delta page } \\
\text { transfer+data } \\
\text { deduplicationt- } \\
\text { VPA } \\
\text { configuration }\end{array}$ & & $\gamma$ & $\gamma$ & & 7 & $\checkmark$ & & $\begin{array}{l}\text { Multipl } \\
\text { e VM }\end{array}$ & yes & $\checkmark$ & $\checkmark$ \\
\hline $\begin{array}{l}\text { Zhanget al } \\
\text { [31] }\end{array}$ & $\begin{array}{l}\text { Precopy-data } \\
\text { duplication }\end{array}$ & & 2 & & & 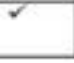 & & & $\begin{array}{l}\text { Sungle } \\
\text { VM }\end{array}$ & No & & \\
\hline
\end{tabular}

Table .2. Comparison of state-of-art existing live migration approaches 
International Journal on Cloud Computing: Services and Architecture (IJCCSA), Vol.3, No.4, August 2013

From Table 2, it is observed that the two important parameters such as VM size and available CPU cycles, have not been taken into consideration during migration process. For efficient migration, all the mentioned parameters should be taken into account and also the performance of the migration algorithm needs to be measured.

\section{CONCLUSION}

The cloud data centers are prominent hosting infrastructure for provisioning of its services. The surging energy consumption of these data centers has become a critical problem from both the economic and environmental standpoints. This paper presents an overview about various dynamic energy management techniques both in hardware and virtualization levels and highlights issues and its significance. However, the hybrid approach that covers both hardware and resource management levels (virtualization) needs to be developed to provide continuous and efficient energy management in virtualized data centers.

\section{REFERENCES}

[1] K.Kant,(2009) “ Data Center Evolution A Tutorial on State of the Art, Issues, and Challenges", Journal of Computer Networks, Vol. 53, pp 2939-2965.

[2] Amazon Elastic Compute Cloud (Amazon EC2), http://aws.amazon.com/ec2/

[3] Microsoft's Cloud Platform (Windows Azure), http://www.windowsazure.com/

[4] J.Kaplan, W.Forrest, \& N.Kindler, (2008) "Revolutionizing Data Center Energy Efficiency. Technical report", McKinsey \& Company

[5] Gartner Says Energy-Related Costs Account for Approximately 12 Percent of Overall Data Center Expenditures,(2011) http: //www.gartner.com/it/ page. Jsp? Id = 1442113

[6] P.Barham, B.Dragovic, K.Fraser, S.Hand, T.Harris, A.Ho, (2003) "Xen and the Art of Virtualization", 19th ACM Symposium on Operating Systems Principles, pp. 164-177,USA

[7] A.Beloglazov, R. Buyya, Y.Lee, A.Zomaya, (2011) "A Taxonomy and Survey of Energy Efficient Data Centers and Cloud Computing", Journal of Advances in Computers. 82, 47-111

[8] G.Luigi, W.Lassonde, S.Khan, G.Valentini, et al, (2011) "An Overview of Energy Efficiency Techniques in Cluster Computing Systems", journal of Cluster computing, Springer

[9] L.Benini, A.Bogliolo, G.Micheli, (2000) "A Survey of Design Techniques for System-Level Dynamic Power Management", IEEE Transactions on Very Large Scale Integration (VLSI) Systems. 8, 299316

[10] S.Gurumurthi, A.Sivasubramaniam, M.Kandemir, et al, (2003) "DRPM: Dynamic Speed Control for Power Management in Server Class Disk", 30th Annual International Symposium on Computer Architecture, pp 169-181. USA

[11] D.Colarelli, D.Grunwald, (2002) "Massive Arrays of Idle Disks for Storage Archives", Proceedings of the ACM/IEEE Conference on SuperComputing. pp 1-11. USA

[12] C.Gunaratne, K. Christensen, B. Nordman, et al, (2008) "Reducing the Energy Consumption of Ethernet with Adaptive Link Rate (ALR)", Journal of IEEE Trans Computer, Vol. 57, 448-461

[13] S. Srikantaiah, A.Kansal, F.Zhao, (2008) "Energy Aware Consolidation for Cloud Computing", Proceedings of the Conference on Power Aware Computing and Systems, USA

[14] C.Hyser, B.McKee, R.Garner, B.Watson, (2008) "Autonomic Virtual Machine Placement in the Data Center", HP laboratories, HPL-2007-189

[15] N.Bobroff, A.Kochut, K.Beaty, "Dynamic Placement of Virtual Machines for Managing SLA violations", IBM T.J Watson Research Center, USA.

[16] A.Beloglazov, R.Buyya, (2010) "Energy Efficient Resource Management in Virtualized Cloud Data Centers", International Conference on Cluster, Cloud and Grid Computing, pp. 826-831 
International Journal on Cloud Computing: Services and Architecture (IJCCSA), Vol.3, No.4, August 2013

[17] T.Wood, G.Levin, P.Shenoy, et al, (2009) "Memory Buddies: Exploiting Page Sharing for Smart Colocation in Virtualized Data Centers", International Conference on Virtual Execution Environments, pp 31-40, USA

[18] X.Meng, V.Pappas, L.Zhang, (2010) "Improving the Scalability of Data Center Networks with Traffic Aware Virtual Machine Placement", International Conference on Information Communications, pp. 1154-1162, USA

[19] M.Sindelar, R.Sitaraman, P.Shenoy, (2011) "Sharing Aware Algorithms for Virtual Machine Colocation", 23rd ACM Symposium on Parallelism in Algorithms and Architectures, pp 367-378, USA

[20] R.Reutiman, J.Sonnek, J.Greensky, A.Chandra, (2009) "Starling Minimizing Communication Overhead in Virtualized Computing Platforms using Decentralized Affinity Aware Migration", Technical Report, University of Minnesota.

[21] A.Corradi, M.Fanelli, L.Foschini, (2012) "VM consolidation: A Real Case Based on Open Stack Cloud", Journal of Future generation of computer system

[22] U.Kousiouris, T.Cacinotta, T.Varvarigou, (2011) "The Effects of Scheduling, Workload type and Consolidation Scenarios on Virtual Machine Performance and their Prediction through Optimized Artificial Neural Networks", Journal of system software, vol. 84, pp. 1270-1291

[23] C.Clark, K.Fraser, S.Hand, J.Hnasen, E.Jul, et al, (2005) " Live Migration of Virtual Mahines", Proceedings of the 2nd Conference on Symposium on Networked Systems Design and Implementation , PP. 273-286, USA

[24] H.Jin, L.Deng, S.Wu, X.Shi, X.Pan, (2009) "Live Virtual Machine Migration with Adaptive Memory Compression", In: IEEE CLUSTER, New Orleans, LA

[25] S.Hacking, B.Hudzia, (2009), "Improving the Live Migration Process of Large Enterprise Applications", International Workshop on Virtualization Technologies in Distributed Computing", pp 51-58, USA

[26] M. Hines, K. Gopalan, (2009) "Post-copy Based Live Virtual Machine Migration Using Adaptive Pre-paging and Dynamic self ballooning", International Conference on Virtual Execution Environments, PP. 51-60, USA

[27] .Sahni, V.Varma, (2012) "A Hybrid Approach to Live Migration of Virtual Machines", International Conference on Cloud Computing in Emerging Markets, India

[28] U.Deshpande, X.Wang, K.Gopalan, (2011) "Live Gang Migration of Virtual Machines", International Conference on High Performance Distributed Computing, pp. 135-146, USA

[29] P.Riteau, C.Morin.et al, (2011) "Shringer: Efficient Wide Area Live Virtual Machine Migration Using Distributed Content Based Addressing", 17th International Conference on Parallel Processing, pp. 431-442, Heidelberg

[30] R.Bradford, E. Kotsovinos, et al,(2007) "Live Wide Area Migration of Virtual Machine including Local Persistent State", 3rd International Conference on Virtual Execution Environments, pp. 169179, USA

[31] X.Zhang, Z.Huo, J.Ma, et al, (2010) "Dan: Exploiting data duplication to accelerate live virtual machine migration" International conference on Cluster Computing, pp. 88-96, Crete.

[32] T.Wood, P. Shenoy, et al, (2011) "Cloudnet: Dynamic Pooling of Cloud Resources by Live WAN Migrations of Virtual Machines", 7th ACM SIGPLAN/SIGOPS International Conference on Virtual Execution Environments, pp. 121-132, USA

[33] Open compute project, http://opencompute.org/2012/11/08/building-a-better-server-chassis

[34] Skiena, S.: The Algorithm Design manual, ISBN 0-387-94860-0ssss

[35] M. Gupta, S. Singh, (2007) "Using Low-Power Modes for Energy Conservation in Ethernet LANs", 26th IEEE International Conference on Computer Communications", pp 2451-2455, AK

[36] B.Heller, S. Seetharaman, P. Mahadevan, (2010) "Elastic Tree: Saving Energy in Data Center Networks", 7th USENIX conference on networked systems design and implementation, pp 1-17, Berkeley, USA

[37] E.Pinheiro, R.Bianchini, (2004) "Energy Conservation Techniques for Disk Array-Based Servers", 18th Annual International Conference on Supercomputing (ICS), pp 68-78, USA 
International Journal on Cloud Computing: Services and Architecture (IJCCSA), Vol.3, No.4, August 2013

\section{Authors}

Veni $\mathbf{T}$ received the B.E Degree in Computer Science and Engineering from Anna University, Chennai in 2008 and the M.E Degree in Computer Science and Engineering from Anna University, Chennai in 2011. Currently, she is pursuing the PhD Degree at the Department of Computer Science and Engineering in National Institute of Technology, Tiruchirappalli, India. Her research interests include Operating System and Cloud Computing.

Mary Saira Bhanu S received the B.E Degree in Electronics and communication from Madurai Kamaraj University in 1986, the M.E Degree in Computer Science from Bharathidasan University in 1989 and the Ph.D. Degree from the Department of Computer Science and Engineering from National Institute of Technology, Tiruchirappalli in

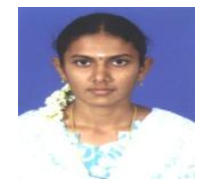
2009.Currently, she is a Associate Professor at the Department of Computer Science and Engineering in National Institute of Technology, Tiruchirappalli, India. Her research interests include OS, Real Time Systems, Distributed Computing, Grid Computing and Cloud C omputing. 